\title{
A simple automatic feeding apparatus for rats
}

\author{
By B. W. LOVELESS, P. WILLIAMS AND F. W. HEATON \\ Department of Biological Sciences, University of Lancaster
}

(Received 2 December I97I - Accepted I8 February 1972)

\begin{abstract}
I. A simple apparatus is described which can be used with the conventional type of experimental rat cage to feed animals automatically.

2. The apparatus consists of a Perspex cylinder with a segment cut from the base which is covered by an aluminium funnel leading to the feeding-pot. An eight-bladed paddle-wheel within the cylinder is rotated once each day by an electric motor and food within the compartments of the wheel is transferred gradually to the pot.
\end{abstract}

A dietary deficiency of many essential nutrients causes anorexia in animals. Allowance is frequently made for this in nutritional studies by pair-feeding control animals, on a daily basis, with an amount of food equal to that consumed by the experimental animals. This practice is, however, only partly satisfactory, because when the food restriction becomes severe control animals eat all their food within 15-30 min after it is provided and then fast for the remainder of the day, whereas deficient animals consume the same amount of food gradually throughout a period of $24 \mathrm{~h}$.

The intermittent pattern of feeding adopted by control animals under these conditions, known as meal-eating, modifies the metabolism of carbohydrates, lipids, proteins and nucleic acids (Fábry, 1967 ). Preliminary experiments undertaken before a detailed investigation of the effect of magnesium deficiency on alkaline phosphatase activity showed that meal-eating altered the activity of the enzyme in several tissues (Loveless and Heaton, unpublished observations), and it therefore became necessary to exclude the influence of eating pattern and ensure that magnesium-deficient and control animals both ate regularly throughout the day.

Automatic feeding equipment for rats has been previously described by König, Schmid \& Schmid (I968) and by Quarterman, Williams \& Humphries (I970), but in both instances it needs special animal cages. We required a device that was applicable to conventional cages and the present paper describes a simple automatic feeder that replaces the food basket in the common type of experimental rat cage. It may be used cither to feed animals regularly throughout the day or to produce specific patterns of meal-eating.

\section{CONSTRUCTION OF FEEDERS}

The feeders are constructed mainly from Perspex and consist of a cylinder mounted on a base-plate, which is secured in the position normally occupied by the food basket by means of spring-loaded clips attached to the bars on top of the cage (P1. I). Inside the cylinder is an eight-bladed paddle-wheel, the bottom edge and end of the blades being bevelled to reduce friction (Pl. 2). The wheel is rotated in an anti-clockwise 
direction by an electric clock motor (Sangamo Weston Ltd, Great Cambridge Road, Enfield; Model 57, I rev./24 h) mounted on the three-quarter-detachable lid of the unit, the drive being provided by a steel bar attached to the shaft of the motor which engages with a groove in the Perspex top to the paddle-wheel when the lid is located on the two steel pins inserted in the top of the cylinder. A segment is cut out from the base-plate corresponding in size to one compartment of the paddle-wheel and over this is secured a triangular aluminium funnel, $15 \mathrm{~cm}$ long, which leads to an earthenware pot on the floor of the cage. The size of the gap between the bottom of the funnel and the base of the feeding-pot, $2.5 \mathrm{~cm}$, is critical to prevent young rats from placing their bodies under the funnel; the pot may be secured to the base of the cage by clips if desired.

When the top of the unit is removed, food can be introduced into the compartments of the paddle-wheel either uniformly or in any desired distribution. Before replacing the lid, the groove in the top of the wheel is aligned with the bar attached to the motor shaft and any small adjustment that is necessary to ensure perfect fit can then be made by rotating the uncovered blade of the wheel as the lid is lowered into position.

\section{DISCUSSION}

The feeder has a capacity for approximately $75 \mathrm{~g}$ of powdered food if it is evenly distributed, and one unit could therefore feed up to five or six adolescent rats, although only three animals can obtain simultaneous access to the feeding-pot. Each compartment in the paddle-wheel traverses the funnel in $3 \mathrm{~h}$, but as the food is pushed continuously by the rotating blades the contents of a single compartment are transferred to the pot gradually over a period of about $2 \mathrm{~h}$. Rats fed $a d l i b$. eat repeatedly throughout the day, the frequency of feeding varying between individual animals from about 2 to $6 \mathrm{~h}$, with a mean interval between feeds of $3.75 \mathrm{~h}$ (Le Magnen, 1967). A feeder with eight compartments is therefore adequate to ensure that animals consume the food provided in a normal manner, although more compartments could be introduced if necessary. Feeders of this design are comparatively cheap and easy to construct and they have been used satisfactorily in this laboratory for over a year.

We thank the Science Research Council for the award of a studentship to B.W.L.

\section{REFERENCES}

Fábry, P. (I 967). In Handbook of Physiology Sect. 6 Alimentary Canal Vol. I, p. 31 [C. F. Code, editor]. Washington, DC: American Physiological Society.

König, K. G., Schmid, P. \& Schmid, R. (1968). Archs oral Biol. 13, 13.

Le Magnen, J. (I967). In Handbook of Physiology Sect. 6 Alimentary Canal Vol. I, p. I I [C. F. Code, editor]. Washington, DC: American Physiological Society.

Quarterman, J., Williams, R. B. \& Humphries, W. R. (1970). Br. F. Nutr. 24, 1049.

\section{EXPLANATION OF PLATES}

PI. I. Automatic feeding apparatus for rats, in operational position.

P1. 2. Components of automatic feeding apparatus for rats: $(a)$ side view, $(b)$ view from above. 


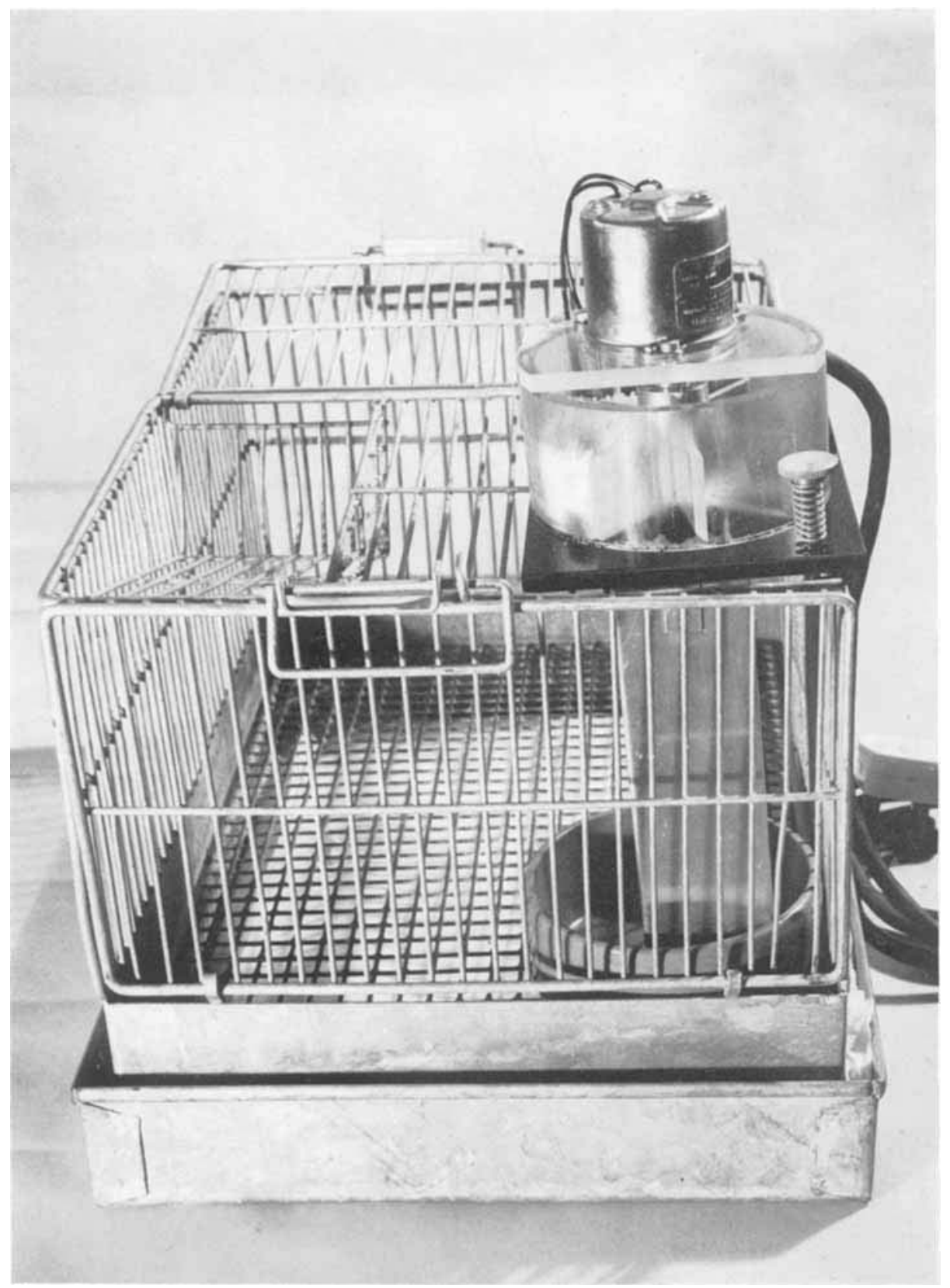



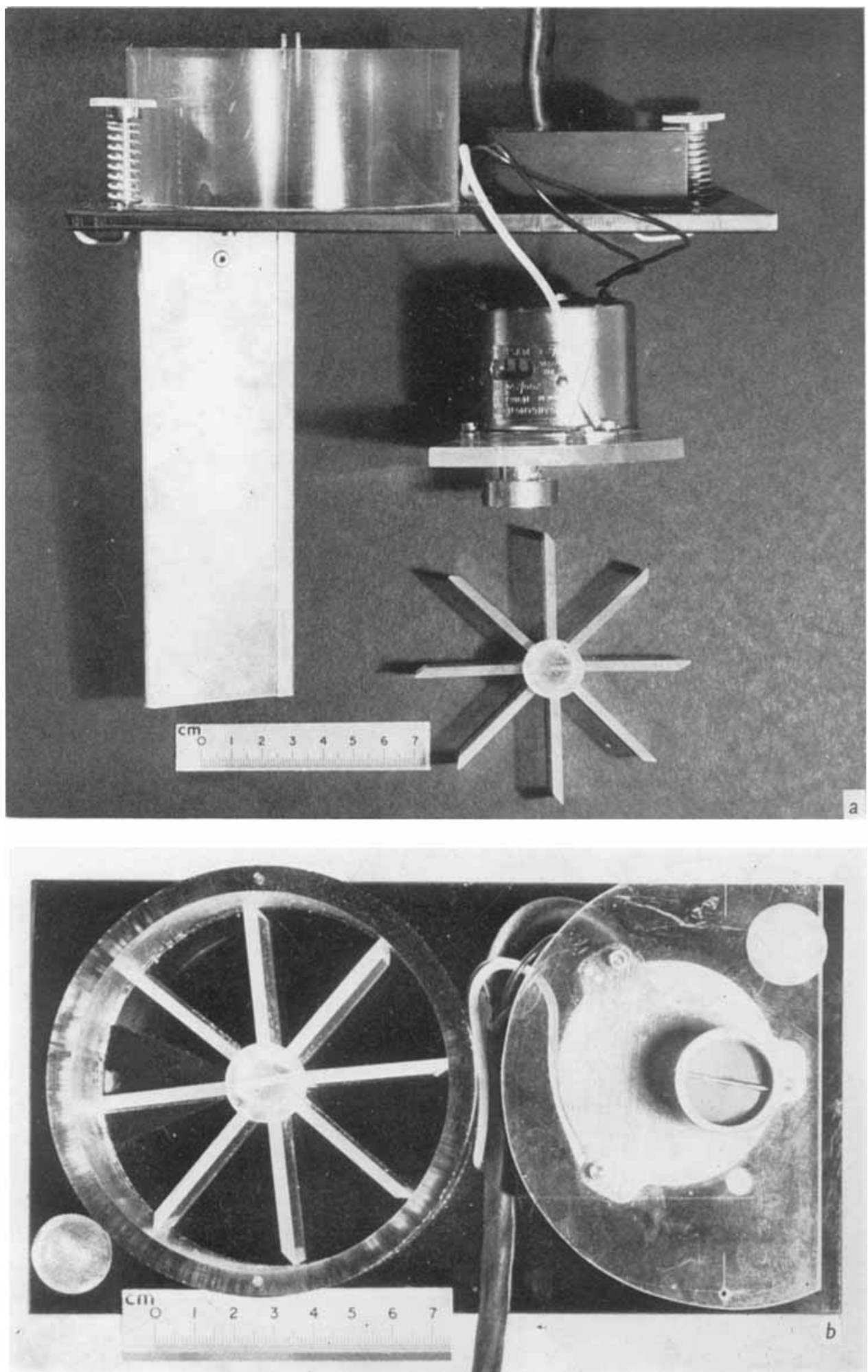

B. W. T.OVEL.ESS, P. WII.I.LAMS ANO E. W. HEATON 